\title{
The Optimal Establishment of Refugee Hierarchical Structure Based on Analytic Hierarchy Process
}

\author{
Ruirui Miao ${ }^{1, a}$ \\ ${ }^{1}$ Department of English, North China Electric Power University, Baoding 071000, China \\ a546475342@qq.com
}

Keywords: Analytic Hierarchy Process, Refugee migration

\begin{abstract}
With the continuous expansion of the European refugee crisis, the policy that EU member states should adopt become a heated topic and urgent priority. This paper aims to analyze the factors effecting refugee migration and set the optimal model to easing the crisis.We address the problem of determining the factors that effect the migration movements of refugees through Analytic Hierarchy Process. The main elements are the recipient countries' resources capacity, the recipient countries' opening points, migration route selection, origin safety degree, types of transportation, individuals' attributes.
\end{abstract}

\section{Introduction}

We investigated the background of the formation of the European refugee crisis.In recent years, the wars led by the US, European countries actively involved in West Asia and North Africa as well as other factors, resulted in the unrest situation in West Asia, North Africa with tribal, ethnic and religious internal conflicts, thereby generating a large number of international refugees across the borderlines.Since 2014, tens of thousands of West African refugees have been continuing to enter European countries, so the refugee problem gradually into the view of European governments and mainstream society.

\section{Problem analysis}

Unlike previous EU's refugee migration policy, we are more focused on the analysis of specific factors related to the refugee crisis and refugees closely. We attempt to calculate the evaluation criteria of the refugee crisis and to study how to improve the existing immigration policy objectively.

We discuss the causes of the refugee crisis in Europe, which paves the way for us to study the factors in refugee resettlement process, in order to determine the refugee resettlement optimization model.The refugee crisis is a direct product of the international politics factors, geopolitical politics factors, geopolitical relations factors, historical factors and religious conflict factors. Among them, the US factor, the European countries, the international pattern, people smuggling organizations, differences in European countries treating refugees and other internal factors are the basic factors that result in refugee flows in Europe.

\section{Our tasks}

Determine parameters and criterions of the refugee crisis in Europe, and analyze the main factors to promote the secure and efficientmovements of refugees, to provide basic reference amount for resolving the refugee crisis.

Integrate refugee movement routes, and create the refugee movement model based on various factorsto determine the flow of refugees movements routes.

\section{Metrics of refugee crises}

By means of Analytic Hierarchy Process (AHP ). We take the following six factors into 
consideration, which lays a foundation for solving the refugee crisis and formulating a reasonable migration policy.

a) The recipient counties' resources capacity:Food, shelters, employment, national economic capacity, population capacity and so on. Resource capacity in different countries is limited, and therefore the ability to accept asylum applications from different countries is limited. According to 2015 EU Member States quotas, we can see that the capacity of the receiving country's resources greatly affect whether refugees can be given reasonable resettlement license.

b) The recipient countries' opening points. Opening entrance mainly includes, ports, airports, border entry and so on. Due to the improper management of the national open entrance, a large number of refugees select from airports, ports, etc. enter countries illegallyprovided by Frontex’s 2015 final report.

c) Migration route selection. Based on the Frontex's statistics, (Figure 1and Figure 2) refugee migration itinerary mainly can be concluded as the following six routes: from the Middle East through (1) West Mediterranean, (2) Central Mediterranean, (3) Eastern Mediterranean, (4) West Balkans, (5) Eastern Borders, and (6) Albania to Greece with different levels of security, road traffic and transportation availability.

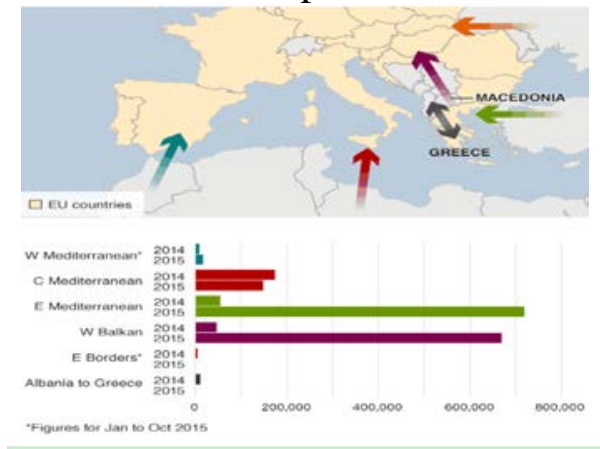

Figure 1: Migrants detected entering the EU Jan-Nov2015

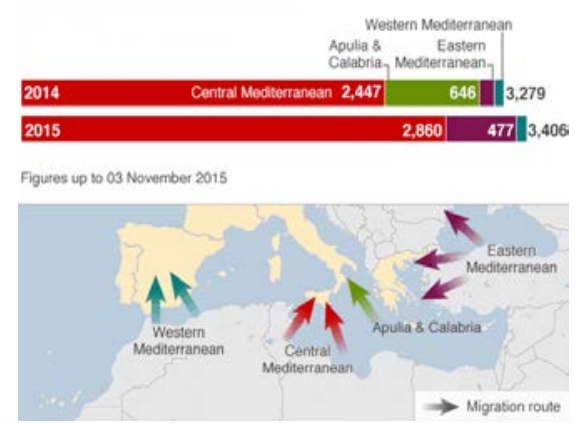

Figure 2: Mediterranean migrant deaths by route

d) Security in the country of origin of refugees. Measure of the safety degree of the country of origin is that whether this country can guarantee democracy, the rule of law, human rights and respect for and protection of minorities. Screening out having a higher or lower degree of security country of origin allows for swifter processing of individual asylum applications from candidates originating from countries considered to be safe across the EU, and for faster returns

e) Types of transportation. In the process of European refugee crisis, land and sea transport are two main ways taking a completely different proportion, shown by the Table 1.(IOM) In marine based refugee resettlement process, due to factors smugglers, illegal boats, weather factors, coastal infrastructure, refugees are under a great risk of death.

Table 1: Recap of Arrivals 2015 (1 January to 31 December 2015)

\begin{tabular}{c|c|c|c} 
Country & Sea & Land & Total \\
\hline Greece & 853650 & 4958 & 858608 \\
\hline Bulgaria & - & 31174 & 31174 \\
\hline Italy & 153842 & - & 153842 \\
\hline Spain & 3845 & - & 3845 \\
\hline Malta & 106 & - & 106 \\
\hline Cyprus & 269 & - & 269 \\
\hline TOTAL & 1011712 & 36132 & 1047844
\end{tabular}

(f) Individuals' attributes: age and gender. We reviewed 2015 European immigrants common health problems shown in the report of World Health Organization and IOM's 2015 European refugee crisis arrivals and deaths report. In the refugee migration process, compared with the opposite , women own a higher mortality rate and female migrants often face specific problems,especially 
maternal, newborn child health, sexual and reproductive health problemas well as the respect of violence.Because of physical vulnerability and the impact of external factors, children and the elderly are in high death mortality.

To analyze the effect of various types of factors and drawn up measures on refugee movement, based on AHP and some intuitive data, we conduct a preliminary analysis of the weight of various types of factors affecting the refugees movement and the weight of efficient measures promoting movement. Steps are as follows:

\section{Establish refugee hierarchical structure}

In our model, we design the target layer as: the criterion layer is the factor of influencing target, B1,B2,B3,B4,B5,B6. Figure 3 is our Hierarchy analysis chart. Our parameters are represented in Table 2.

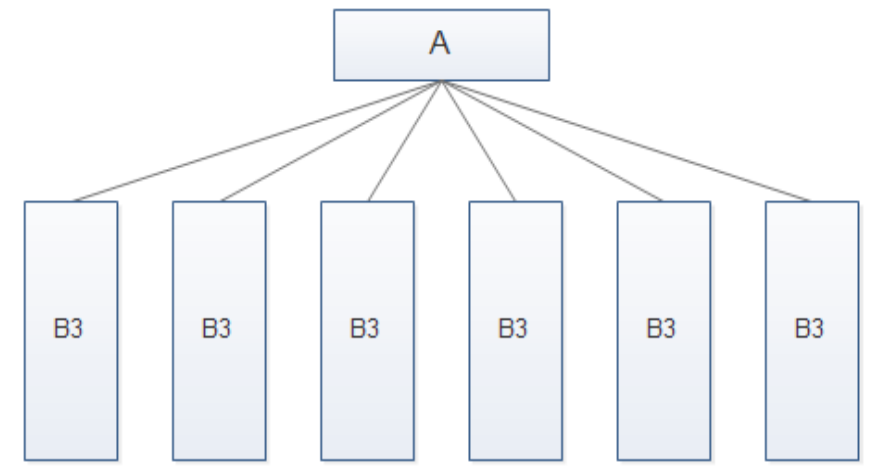

Figure 3 Hierarchy analysis chart

Table 2: Model Parameter

\begin{tabular}{ll}
\hline Parameter & Meaning \\
\hline A & Influencing refugee migration \\
B1 & Individuals' attributes \\
B2 & Types of transportation \\
B3 & Migration route selection \\
B4 & The recipient countries' opening points \\
B5 & The recipient countries' resources capacity \\
B6 & Origin safety degree \\
\hline
\end{tabular}

\section{Construct Judgment Matrix}

In comparison to the size of $\mathrm{n}$ factors' effects on the target (Z), each time we take two factors $x_{i}$, $x_{j}$, by $a_{i j}$ to express influence ratio of $x_{i}$ and $x_{j}$ to Z, and all comparison resultsare concluded in Matrix $\mathbf{A}=\left(a_{i j}\right) \times m \times n$

\section{Single-level sorting and Consistency check}

\subsection{The consistency test of the judgment matrix follows these steps:}

1) Calculate consistency index CI

Where:

a $-6 * 6$ matrix storing various factors' influence ratio on the refugee migration

cr1 -Matrix a's consistency proportion

ci1 -Matrix a’s consistency index

w1 -Weight of the influences exerted by various factors to the target

2) Find the corresponding average random consistency index

For $n=1,2, \ldots, 9$, US operations research expert T. L. Saatygives the value of RI, shown as follows: 


\begin{tabular}{|c|c|c|c|c|c|c|c|c|c|}
\hline $\mathrm{N}$ & 1 & 2 & 3 & 4 & 5 & 6 & 7 & 8 & 9 \\
\hline $\mathrm{RI}$ & 0 & 0 & 0.58 & 0.90 & 1.12 & 1.24 & 1.32 & 1.41 & 1.45 \\
\hline
\end{tabular}

3) Calculate the consistency ratio CR

$$
C R=\frac{C I}{R I}
$$

When CR $<0.1$, it is considered the consistency of judgment matrix is acceptable, otherwise respond appropriately amended judgment matrix.

\subsection{Calculation results}

1) The weight of elements' influences on the target

$$
A=0.0286 B_{1}+0.0785 B_{2}+0.1636 B_{3}+0.2973 B_{4}+0.3014 B_{5}+0.1306 B_{6}
$$

2) Consistency proportion $\mathbf{c r 1}=\mathbf{0 . 0 7 2 2}$

\section{Analysis and conclusion}

By using the analytic hierarchy process and survey data, we come to the conclusion (a) the recipient countries' resources capacity (b) the recipient countries' opening points (c) migration route selection (d) origin safety degree ( e) types of transportation (f) individuals' attributes have a profound effect on refugee crisis, especially factor (a). C1 C2 C3 will ease the tense of the refugee crisis, having a prominent impact on factors.

\section{References}

[1] Hal R.Varian: Intermediate Microeconomics (W. W. Norton \& Company, 2005).

[2] Hans-Jürgen Zimmermann: Fuzzy Set Theory and its Applications(2001-11). 